\title{
MENEROKA ASPEK RELIGI DRAMA GRAFITO KARYA AKHUDIAT
}

\author{
Dian Roesmiati
}

Balai Bahasa Jawa Timur, dianroes@gmail.com

\begin{abstract}
ABSTRAK
Penelitian ini bertujuan mendeskripsikan aspek religi drama Grafito karya Akhudiat dan mendeskripsikan konflik antartokoh yang berkaitan dengan aspek religi. Tema-tema religi merupakan sesuatu yang lazim muncul dalam karya sastra. Bersikap religiositas adalah berserah diri pada kekuatan yang lebih besar untuk menciptakan kebahagiaan yang bersifat pribadi. Penelitian ini berkaitan dengan teori sosiologi sastra untuk menganalisis naskah drama. Sumber data penelitian adalah Grafito yang terdapat dalam Antologi 5 Lakon Akhudiat. Metode yang digunakan adalah deskriptif kualitatif. Teknik pengumpulan data dalam penelitian ini menggunakan teknik kepustakaan, yaitu membaca naskah drama Grafito secara intens dan menginterpretasi serta memahami naskah drama tersebut, kemudian menganalisis. Hasil temuan penelitian ini adalah adanya konfik antartokoh yang berkaitan dengan beda pendapat tentang agama. Perbedaan agama dalam suatu pernikahan menjadi tema sentral drama Grafito. Analisis aspek religi naskah drama Grafito menghasilkan adanya hubungan dan respons religi dalam drama tersebut. Akhudiat sebagai pengarang berhasil membuka wawasan pembaca tentang "perbedaan yang indah" dalam suatu pernikahan beda agama. Penggambaran aspek religi muncul melalui peristiwaperistiwa dalam dialog antartokoh. Berlatar belakang konflik pernikahan beda agama, yaitu Islam dan Kristen, drama Grafito menunjukkan keuniversalan tema tentang manusia dan Tuhan. Grafito karya Akhudiat ini dapat digolongkan sebagai drama bergenre komedi satire.
\end{abstract}

Kata kunci: Aspek religi, naskah drama, komedi satire

\section{PENDAHULUAN}

Akhudiat adalah sastrawan Jawa Timur yang sampai saat ini masih mencintai dunia drama dan teater. Salah satu karya monumentalnya adalah Grafito yang pernah memenangi lomba penulisan naskah sandiwara, Dewan Kesenian Jakarta tahun 1972. Selain Grafito, naskah drama Jaka Tarub (1974), Rumah Tak Beratap (1974), Bui (1975), dan RE (1977) adalah karya Akhudiat yang berturut-turut mendapat penghargaan dan mengantarkannya mengikuti International Writing Program, University of Iowa, USA tahun 1975. Penulis 
naskah dan sutradara Teater Bengkel Muda era 70-an ini sampai sekarang masih aktif menulis. Sederet prestasi yang diperoleh Akhudiat tersebut menunjukkan bahwa Akhudiat termasuk sastrawan yang penting dan luar biasa yang dimiliki Jawa Timur. Naskah dramanya menjadi tonggak sejarah sastra drama Indonesia. Alasan memilih Grafito sebagai objek penelitian karena peneliti ingin "meneroka" (KBBI: 'menjelajahi') dunia religi dalam naskah drama tersebut. Grafito menarik untuk dikaji karena menukilkan tema pernikahan beda agama. Konflik yang dialami antartokoh begitu rumit dan menarik untuk dibahas. Selain itu, Grafito penuh dengan dialog-dialog segar yang dibumbui humor satire. Drama Grafito memiliki karakteristik yang berbeda dengan naskah drama lain sehingga dapat dikategorikan sebagai naskah drama yang berkualitas.

Sastra dalam bentuk karya apapun selain mengandung gagasan terdapat juga pandangan tentang moral atau amanat. Dalam pengertian ini, karya sastra pun dapat dipandang sebagai sarana komunikasi. Bila dibandingkan dengan sarana komunikasi yang lain, baik lisan maupun tulisan, karya sastra merupakan salah satu ujud karya seni yang sebagian besar mengembangkan tujuan estetik dan mempunyai kekhususan sendiri dalam hal menyampaikan pesan-pesan religius.

Pada karya sastra terdapat juga pesan yang hendak disampaikan pengarang, termasuk pesan religi yang di dalam karya fiksi menawarkan pesan religius. Pada sebuah karya sastra sering terdapat lebih dari satu pesan religius yang disampaikan. Meneroka religius berkaitan dengan adanya kenyataan merosotnya kualitas penghayatan orang dalam beragama atau berkaitan dengan hilangnya dimensi kedalaman dan hakikat dasar yang universal dari religi. Jadi, religiusitas merupakan kritik terhadap kualitas keberagamaan seseorang di samping terhadap agama sebagai lembaga dan ajaranNya. Religiusitas dimaksud sebagai pembuka jalan agar kehidupan orang yang beragama makin intens. Antara religiusitas dengan perikemanusiaan merupakan hal yang berbeda tetapi secara

${ }^{*}$ Ahmad S Rumi, Reorientasi Nilai Religius dalam Karya Sastra, 6 Juli 2017 pukul 15.07 WIB 
esensial sangat erat hubungannya, yaitu "penuntunan manusia ke arah segala makna yang baik" merupakan salah satu ciri religiusitas yang otentik. Seseorang mampu menyikapi dan menyelesaikan permaslahan dengan baik.

Mangunwijaya (dalam Lathief, 2008) mengemukakan bahwa segala sastra adalah religius. Religius diambil dari bahasa Latin relego, dimaksudkan dengan menimbang kembali atau prihatin tentang sesuatu hal. Seorang religius diartikan sebagai manusia yang berarti, yang berhati nurani serius, saleh, teliti, dan penuh dengan pertimbangan spiritual (Lathief, 2008). Religiositas lebih melihat aspek yang 'di dalam lubuk hati' moving in the deep heart'.

Dengan demikian, sikap religius ini lebih mengajuk pada pribadi seseorang dengan Khaliqnya, bertata laku sesuai dengan karsa Tuhan (Lathief, 2008). Sastra religius adalah sastra yang mengandung nilai-nilai ajaran agama, moralitas.

Kehidupan manusia sangat kompleks dengan berbagai masalah. Beberapa masalah kehidupan pada manusia mencakup hubungan antarmasyarakat, antarmanusia, manusia dan Tuhan-Nya, dan antarperistiwa yang terjadi dalam batin seseorang (Nurgiyantoro, 2010:323). Aspek religi yang terdapat dalam karya sastra dapat memberi contoh kepada masyarakat untuk selalu taat kepada Tuhan. Aspek religi dalam karya sastra memberikan pengaruh yang baik terhadap perilaku moral pembaca dan juga masyarakat. Aspek religi dalam drama Grafito karya Akhudiat dibagi menjadi dua, yaitu hubungan antara manusia dengan Tuhan dan hubungan antara manusia dengan manusia. Hubungan manusia dengan Tuhan adalah hubungan vertikal yang menghubungkan perasaan manusia dengan Tuhan dan diujudkan dengan melaksanakan perintahNya serta menjauhi laranganNya. Hubungan manusia dengan manusia adalah hubungan horizontal antara manusia yang satu dengan yang lain dan terdapat dalam suatu hubungan masyarakat tertentu 
Stanton (2012:22 - 46) membedakan unsur pembangun sebuah cerita ke dalam tiga bagian, yaitu tema, fakta cerita, dan sarana cerita. Tema adalah makna cerita yang khusus menerangkan sebagian besar unsurnya dengan sederhana. Fakta (fact) meliputi alur, latar, dan penokohan. Sarana sastra (literary device) adalah teknik yang digunakan pengarang untuk memilih dan menyusun detaildetail menjadi pola yang bermakna dalam sebuah cerita, fakta meliputi karakter (tokoh cerita), plot, dan latar. Ketiga unsur tersebut harus dipandang sebagai satu kesatuan dalam rangkaian keseluruhan cerita, bukan sebagai sesuatu yang berdiri sendiri dan terpisah satu dengan yang lain. Adapun analisis dalam penelitian ini difokuskan pada tema, penokohan, dan alur karena unsur-unsur tersebut lebih dominan membentuk kesatuan makna yang bulat dalam cerita. Pendekatan sosiologi sastra adalah menganalisis manusia dalam masyarakat dengan proses pemahaman mulai dari masyarakat ke individu. Pendekatan sosiologis juga memiliki implikasi metodologis berupa pemahaman mendasar mengenai kehidupan manusia dalam masyarakat (Ratna:2007).

Menurut Nurgiyantoro (2010), tokoh cerita adalah orang-orang yang ditampilkan dalam suatu karya naratif atau drama dan pembaca dapat menafsirkan kualitas moral dan kecenderungan tertentu seperti yang diekspresikan dalam ucapan dan apa yang dilakukan dalam tindakan. Penokohan merupakan bagian terpenting dalam membangun sebuah cerita karena berperan menyampaikan ide, alur, dan tema. Secara institusional, objek sosiologi dan sastra adalah manusia dalam masyarakat. Setakat pendapat Ian Watt bahwa ada tiga pendekatan dalam sosiologi. Pertama, konteks sosial pengarang, kedua sastra sebagai cermin masyarakat, dan ketiga fungsi sosial sastra.

Masalah religi mejadi sumber konflik antartokoh dalam drama. Grafito mengisahkan tentang suka duka percintaan Limbo (pemuda Katolik) dan Ayesha (Islam). Namun, cinta mereka mendapat halangan ketika hendak diujudkan dalam jenjang pernikahan. Kiai dan Pastur setempat tidak bersedia menikahkan karena 
perbedaan agama. Penyelesaian konflik dalam Grafito adalah kehadiran tokoh Pawang, Kamajaya dan Ratih yang mau menikahkan mereka. Munculnya tokohtokoh Kamaja, Ratih , dan Pawang membuktikan bahwa Grafito diilhami oleh religi Jawa, yaitu kepercayaan terhadap kekuatan supranatural atas dewa-dewi yang dikenal dalam budaya Jawa. Dewi Ratih dan Kamajaya dikenal sebagai simbol cinta kasih dalam masyarakat Jawa tradisional. Dewi Ratih dan Kamajaya dipercaya oleh sebagian masyarakat tradisional Jawa memiliki kekuatan supranatural untuk membangkitkan rasa cinta pada seseorang. Selain itu, Dewi Ratih dan Kamajaya digunakan untuk menggambarkan simbol keserasian dan kesempurnaan hubungan cinta sepasang kekasih. Religi sebagai sumber konflik mewarnai drama Grafito. Penelitian ini bertujuan mendeskripsikan aspek religi drama Grafito dan konflik antartokoh terkait masalah beda agama.

Penelitian ini merupakan penelitian kualitatif dengan pendekatan deskriptif kualitatif, yaitu penelitian yang mendeskripsikan secara sistematis, faktual, dan akurat mengenai fakta-fakta dan hubungan kausal dari fenomena yang diteliti (Sutopo, 2002) dengan menggunakan teori sosiologi sastra. Sumber data penelitian ini ada dua, yaitu sumber data primer dan sekunder. Sumber data primer adalah buku Antologi 5 Lakon Akhudiat yang diterbitkan oleh PAGAN PRESS tahun 2014, khususnya halaman 1-65. Data penelitian ini berujud informasi berupa kalimat atau dialog-dialog para tokoh dalam drama. Adapun sumber data sekunder yang digunakan dalam penelitian ini adalah artikel di internet yang berkaitan dengan Akhudiat. Pengumpulan data dalam penelitian ini menggunakan teknik pustaka, simak, dan teknik catat.

\section{PEMBAHASAN}

Hasil analisis drama Grafito karya Akhudiat meliputi unsur intrinsik drama meliputi tema, tokoh, dan alur. Tema Grafito adalah "perkawinan beda agama". 
Tema ini tersirat dalam dialog-dialog yang dilontarkan para tokohnya. Adapun tokoh dalam Grafito adalah Limbo dan Ayesha. Kedua orang tersebut merupakan tokoh utama yang banyak dikenai masalah. Ada beberapa tokoh yang juga berperan menghidupkan konflik cerita, seperti Kyai dan Pastur. Alur cerita Grafito termasuk alur lurus dan kronologis karena cerita diawali pertemuan Limbo dan Ayesha dan kemudian menyeret ke permasalahan inti, yaitu keinginan keduanya untuk menikah. Konflik cerita terjadi ketika keinginan mereka untuk menikah terhalang perbedaan agama.

\section{LIMBO \& AYESHA}

Dan Limbo, figur jalanan, melamar Ayesha di trotoar (berpegangan tangan, berkasih mesra.

(Grafito:33)

\section{LIMBO}

Demi Tuhan, di tangan-Nya segala cinta bersumber, ayo, kita ke penghulu, Ayesha butuh restu.

AYESHA

Juga ke pastur, untuk Limbo, beliau akur, kita bersyukur.

\section{KOOR}

Wahai Tuhan nan Budiman, kami pengantin, kami calon-calon pengantin, kami cucu Hawa dan Adam, bukan kelinci percobaan.

(Grafito:34)

Limbo dan Ayesha adalah sepasang kekasih yang ingin menyatukan hubungan mereka ke jenjang perkawinan. Niat mereka tulus dan baik, tetapi perbedaan prinsip membuat semua rencana tersebut kacau. Perbedaan pendapat tentang 
Dian Roesmiati, Meneroka Aspek Religi... (hlm. 73-90)

perkawinan antara Limbo dan Ayesha dengan Kiai dan Pastur tidak menemukan jalan keluar. Satu sama lain bersikukuh dengan pendapatnya masing-masing.

\section{PASTUR}

Engkau Katolik?

LIMBO

Katolik

PASTUR

Bersumpahlah demi Kristus

LIMBO

Saya sumpah

PASTUR

Engkau Ayesha?

AYESHA

Saya, Pastur

PASTUR

Engkau, Katolik?

AYESHA

Bukan. Saya muslimat

PASTUR

Hah?

AYESHA

Islam

PASTUR

Lalu, engkau akan mengikuti suamimu?

\section{AYESHA}

Saya ikuti Limbo sebagai suami saya, tetapi ....

http://journal.unesa.ac.id/index.php/paramasastra| 79 
LIMBO menyela

Rama Pastur, kami tetap memeluk keyakinan kami masing-masing

LIMBO

Saya patuh Rama. Itulah sebabnyaa ke Gereja memohon berkat.

PASTUR

Tidak boleh jadi. Calon istrimu belum menyatakan diri sebagai Nasrani.

(Grafito:47-49)

\section{Aspek Religi Drama Grafito}

Nilai religius adalah nilai yang berkaitan antara manusia dengan Tuhan seperti perasaan takut berdosa dan mengakui kebesaran Tuhan. Nilai religius adalah sifatsifat manusia atau tokoh cerita yang senantiasa berusaha mendekatkan diri kepada Tuhan. Dengan demikian, firman Tuhan akan selalu terbayang pada tiap langkah para tokohnya. Oleh karena itu, manusia yang religius adalah manusia yang pandangan, sikap, dan perilaku di dunia selalu berdasarkan firman Tuhan.

Menurut The Word Book Dictionary, kata religioucity berarti 'religious feeling or sentiment' atau perasaan keagamaan. Religi lebih luas artinya karena lebih mengarah pada masalah personalitas dan bersifat dinamis karena lebih menonjolkan eksistensinya sebagai manusia. Mangunwijaya (dalam Nurgiyantoro, 2010:326 - 327) mengemukakan bahwa perbedaan agama dan religiusitas. Agama lebih menunjukkan pada kelembagaan kebaktian pada Tuhan dengan hukumhukum yang resmi. Sedangkan, religiusitas bersifat mengatasi lebih dalam dan lebih luas dari agama yang tampak, formal dan resmi. Religiusitas berkaitan dengan kebebasan orang untuk menjaga kualitas keberagaman jika dilihat dari dimensi yang paling dalam dan personal yang acapkali berada di luar kategorikategori ajaran agama. Religiositas adalah suatu perasaan keagamaan yang lebih mengarah pada eksistensinya sebagai manusia karena bersifat personalitas dan 
cakupannya lebih luas daripada agama yang hanya terbatas pada ajaran-jaran dan pertautan.

Dalam penelitian ini, pengertian agama dan religi dipakai dalam pengertian yang sama. Perbedaan pengertian sebagaimana dikemukakan Mangunwijaya tersebut hanyalah perbedaan gradasi dalam hal intensitas atau tingkat kedalaman penghayatan. Akan tetapi, pengertian agama dan religi berhubungan dengan penghayatan terhadap Tuhan dan ketuhanan. Penghayatan ini berdasar pada pemahaman nilai-nlai yang bersifat tradisional keagamaan atau religi.

Durkheim (2011:49 - 56) juga tidak membedakan agama dan religi. Menurutnya satu konsep yang biasanya dipandang menjadi karakteristik segala sesuatu yang religius adalah konsep supernatural, yaitu hal-ikhwal yang berada di luar kemampuan pemahaman manusia, dunia misteri yang tidak dapat diketahui dan dicerap indera. Karena itu, lebih baik menggunakan sesuatu yang spiritual sebagai definisi minimum untuk agama. Spritual harus dimengerti sebagai subjeksubjek berkesadaran yang memiliki kemampuan melebihi kemampuan manusia biasa, seperti arwah, jin, setan, dan dewa-dewi dapat dimasukkan dalam definisi tersebut. Religi atau agama menjadi komponen yang turut membentuk karya sastra. Lebih-lebih dalam masyarakat yang religius atau agamis, atmosfer religi atau agama dominan menyelimuti sendi kehidupan masyarakat.

Larangan menikah beda agama sudah bergulir tahun 1970-an. Untuk merespons hal tersebut, pemerintah mengesahkan UU No. 1 Tahun 1974 tentang Perkawinan. Namun, dalam kenyataan sehari-hari, dalam kehidupan beragama, perdebatan kawin beda agama masih terus berlangsung. Dalam Grafito menceritakan tentang pertemuan Limbo (pemuda Katolik) dan Ayesha (Islam) yang saling jatuh cinta. Namun sayang cinta mereka terhalang aturan agama. Baik Kiai maupun Pastur tidak bersedia menikahkan karena perbedaan agama. 
Masyarakat Indonesia merupakan masyarakat yang beragam, baik budaya, suku, dan agama. Kontak antargolongan yang berbeda tersebut sering terjadi di masyarakat. Fenomena perkawinan campuran banyak mengundang perhatian dan perdebatan. Merunut hal tersebut, proses penciptaan drama Grafito diilhami realitas kehidupan beragama di masyarakat, yaitu perkawinan beda agama.

\section{KYAI}

Baiklah (kepada Limbo) Limbo, calon pengantin laki-laki silakan membaca Syahadat sebagai pernyataan engkau seorang muslim

\section{Limbo agak bingung}

AYESHA

(menyela) Calon suami saya Katolik, Kyai.

KYAI

(terbelalak) Ya robbi, kamu sendiri, Ayesha.

\section{AYESHA}

Muslimat, Kyai. Saya murid ngaji Nyai Siti.

\section{KYAI}

Ini tidak bisa jadi, Ayesha. Kau, kan, sudah faham seorang muslimat dilarang menikah dan dinikahi laki-laki kafir.

AYESHA

Keliru, Kyai. Dia bukan kafir. Ahli kitab

KYAI

Maksud saya, baik dia kafir atau ahli kitab dilarang menikahi muslimat.

Ini hukum Tuhan. Kecuali laki-laki itu bersedia masuk Islam.

AYESHA

Kami tetap dalam keyakinan agama masing-masing.

AYESHA

82 | http://journal.unesa.ac.id/index.php/paramasastra 
Dian Roesmiati, Meneroka Aspek Religi... (hlm. 73-90)

Tapi kenapa seorang laki-laki Islam boleh kawin dengan wanita bukan Islam? KYAI

Itu sudah ketentuan Kitab Suci

KYAI

Agama bukan selalu pengertian yang bisa dimengerti. Cukup diyakini. Iman namanya.

AYESHA

Apakah iman sama dengan keyakinan sempit, Kyai.

KYAI

Iman ialah pernyataan sah pasrah manusia kepada Al Khaliq.

\section{AYESHA}

Tetapi Tuhan tidak menyempitkan gerak bebas manusia, makhluk yang dikarunia keistimewaan. Al Aql. Akal fikiran dengan segala manifestasinya.

\section{KYAI}

Al Aql dibatasi oleh An Naql. Wahyu Tuhan dan sabda rasul.

(Grafito:41-42)

(1) Hubungan Manusia dengan Tuhan

Hubungan manusia dengan Allah dalam ajaran Islam bersifat timbal balik, yaitu manusia melakukan hubungan dengan Tuhan dan Tuhan melakukan hubungan dengan manusia. Tujuannya adalah untuk ibadah. Manusia diperintahkan berbuat menurut aturan yang telah ditetapkan Allah/Tuhan. Jika manusia menyimpang dari aturan, ia akan tercela, baik dalm kehidupan di dunia maupun di akhirat. Untuk mengetahui aspek religi dalam sebuah karya sastra (drama) bukan hal yang mudah karena diperlukan kemampuan mengetahui konsep religi tersebut. Pada 
prinsipnya religi adalah penyerahan diri pada Tuhan dalam keyakinan bahwa manusia bergantung pada Tuhan, bahwa manusia tidak mampu memperoleh keselamatan dengan kekuatannya sendiri.

Berikut hubungan manusia dengan Tuhan terkait aspek religi drama Grafito.

Akidah adalah kepercayaan dan keyakinan terhadap Allah serta beriman dengan nama-namanya dan segala sifat-sifatnya. Patuh dan taat segala jaran dan petunjuknya. Dengan begitu akidah Islam ialah keimanan dan keyakinan terhadap Allah dan rasulnya serta apa yang dibawa oleh rasul tersebut dilaksanakn dalam kehidupan. Akidah dalam drama Grafito dapat dirinci sebagai berikut.

(a) Cinta kepada Allah

Kata cinta kepada Allah mempunyai arti merindukan Allah. Cinta kepada Allah dalam drama Grafito ditunjukkan oleh Limbo dan Ayesha. Keduanya sangat taat pada ajaran agama masing-masing. Ketika dihadapkan pada perbedaan prinsip, yaitu perbedaan agama, Limbo dan Ayesha tetap saling menghormati perbedaan yang ada.

(b) Percaya kepada Allah

Kata "percaya" kepada Allah mempunyai arti 'mengakui atau yakin bahwa Allah itu ada'.

\section{LIMBO}

Rama, saya menghormati Ayesha karena teguh menjalankan Islamnya. Saya hendak merumuskan toleransi bukan sekadar basa-basi zaman diskusi, tetapi langsung praktik sehari-hari.

(Grafito:50)

\section{KOOR}

Rama Pastur, kami datang dengan damai, untuk mohon berkat, bagi cinta Limbo dan Ayesha, agar selamat dunia akhirat

84 | http://journal.unesa.ac.id/index.php/paramasastra 
Dian Roesmiati, Meneroka Aspek Religi... (hlm. 73-90)

(Grafito:50)

Pada kutipan tersebut menggambarkan kepercayaan Limbo dan Ayesha kepada Allah bahwa Allah akan mengabulkan permohonan hambaNya agar selamat di dunia dan akhirat. Limbo dan Ayesha percaya kebesaran Allah. Tidak ada sesuatu yang sulit bagi Allah.

c. Kata doa berarti 'permohonan (harapan, permintaan, pujian) kepada Allah. Aspek religius berdoa dalam drama Grafito karya Akhudiat terlihat pada data berikut.

\author{
PASTUR \\ (muncul mengangkat tangan berdoa) \\ Yesus Kristus, Raja Diraja \\ Inilah amsal Kain dan Kabil \\ Putera-putera Adam yang saling bertikam \\ Junjungan segala Raja
}

Gereja-Mu terlalu sempit menampung mereka

Yang terlahir dari dosa dan dosa

Roh Kudus

Datanglah menghampiri hati mereka

Hembuskan angin nyaman kebun zaitun sorga

Amen...

(Grafito:45)

Berdoa merupakan bagian dari ibadah. Pengertian ibadah dapat ditemukan melalui pemahaman bahwa kesadaran beragama pada manusia membawa konsekuensi manusia itu melakukan penghambaan kepada Tuhannya. Dalam ajaran Islam 
maupun Katolik, manusia itu diciptakan untuk menghamba kepada Allah atau dengan kata lain beribadah kepada Allah. Manusia yang menjalani hidup beribadah kepada Allah itu tiada lain manusia yang berada pada jalan yang lurus. Manusia yang berpegang teguh kepada apa yang diwahyukan Allah maka ia berada pada jalan yang lurus. Dengan demikian, segala sesuatu yang disebut dengan manusia hidup beribadah kepada Allah itu ialah manusia yang dalam menjalani hidupnya selalu berpegang teguh kepada Allah. Ibadah merupakan perendahan diri kepada Allah dengan cara melaksanakan dan menjauhi segala larangannya, serta mengimplementasikan dalam bentuk berdoa kepada Allah.

\section{(2) Hubungan manusia dengan manusia}

Hubungan manusia dengan manusia pada drama Grafito di antaranya: (1) tolong menolong merupakan perintah Allah yang memerintahkan manusia agar saling menolong dalam hal kebaikan; (2) bergaul dengan orang lain dibolehkan dalam agama asalkan berteman dengan orang yang baik; (3) memberi salam kepada orang lain adalah suatu kebaikan memberi salam kepada orang lain berarti mendoakan orang lain dan orang lain yang menjawab salam berarti juga mendoakan orang yang memberi salam; dan (4) memberi nasihat adalah melakukan perbuatan baik dan mencegah perbuatan buruk yang dilakukan oleh diri sendiri atau orang lain.

Drama Grafito berakhir dengan pernikahan Limbo dan Ayesha atas restu Dewi Ratih dan Kamajaya. Keduanya adalah sepasang dewa dalam mitologi yang dipercaya sebagai dewa-dewi asmara. Limbo dan Ayesha yang gagal meminta Kiai dan Pastur untuk menikahkan mereka, akhirnya ditolong oleh tokoh Pawang.

KOOR menggumamkan lagu upacara wejang asmara.

KAMAJAYA \& RATIH memadukan calon pengantin jadi pengantin. Wejanganwejangan, mantra-mantra, ramuan-ramuan, dsb. dsb. dalam adegan bisu. 
Dian Roesmiati, Meneroka Aspek Religi... (hlm. 73-90)

PAWANG mengepulkan asap pedupaan makin tebal.

KOOR makin syahdu dan memeras haru.

KAMAJAYA \&RATIH tiba-tiba hilang dari pandangan

Persis asap hilang

LIMBO \& AYESHA menjelma pengantin sempurna

(Grafito: 62)

Hubungan manusia dengan manusia dilakukan oleh Limbo dan Ayesha ketika meminta bantuan Pawang untuk mencari solusi masalahnya. Namun, tokoh Pawang berusaha mewujudkan keinginan Limbo dan Ayesha menggunakan kekuatan gaib. Dalam budaya Jawa tradisional, kepercayaan kepada hal gaib masih melekat kuat. Religi adalah suatu sistem simbol-simbol yang dengan sarana tersebut manusia berkomunikasi dengan jagat raya. Pada prinsipnya, religi memuat lima unsur, yaitu adanya emosi; keyakinan; upacara; peralatan; dan pemeluk atau penganut. Seperti kita ketahui, Akhudiat dikenal sebagai sastrawan Jawa Timur yang lahir di Banyuwangi. Tanah kelahirannya di Banyuwangi mungkin yang menjadikan karya-karyanya banyak berbicara tentang budaya, masalah agama dan religi, serta kepercayaan Jawa. Seperti dalam Grafito, hampir dalam keseluruhan adegan cerita berwarna religi, baik Islam, Nasrani, dan kepercayaan Jawa.

\section{LAPANGAN}

KOOR duduk melingkar sikap samadi LIMBO \& AYESHA di tengah

PAWANG mengatur upacara, membakar kemenyan, Menabur dupa, menyalakan lilin-lilin, menyusun sajen-sajen. 
Memimpin samadi

PAWANG

Hong wi lahing

Sekaring bawono

Segolo langgeng

PAWANG

Duhai, dewa-dewi asmara

Puasaka Nusantara

Turunlah barang sekejap

Ke Mayapada

PAWANG menambah dupa dan kemenyan

DEWI RATIH \& DEWA KAMAJAYA turun dari kayangan...

(Grafito:56-58)

Drama Grafito memang tergolong drama absurd, yaitu drama yang 'tidak masuk akal' dan tidak dapat dinalar. Namun demikian adanya, seperti pendapat Damono (2009) bahwa Grafito dikenal sebagai naskah eksperimental, nonkonvensional, dan radikal. Selain itu, juga dikenal sebagai naskah drama yang absurd (Soemanto, 2007:47) serta menampilkan warna daerah atau budaya tradisional (Damono, 2009:80-84). Drama ini disajikan dengan kelakar atau humor yang bernada satire, yaitu sindiran atau ejekan terhadap suatu keadaan yang disajikan dengan guyonan. Hal ini terlihat sejak awal hingga akhir cerita, dialog-dialog para tokohnya terasa "segar" penuh kritik dan menggelitik.

Akhir cerita Grafito adalah kebahagiaan bagi Limbo dan Ayesha, tetapi sangat bertentangan dengan yang diharapkan oleh pembaca. Pilihan menikah dengan tradisi yang percaya dengan kekuatan gaib merupakan sindiran bagi masyarakat saat ini. Konflik dan perdebatan yang panjang tentang agama 
menimbulkan sikap apatis bagi Limbo dan Ayesha. Konflik religi yang dialami tokoh-tokoh Grafito ada pada keseluruhan cerita. Kalaupun di akhir cerita, Limbo dan Ayesha dipersatukan oleh kepercayaan gaib dan kepercayaan terhadap dewadewa ini membuktikan bahwa Grafito sangat diilhami oleh tradisi budaya Jawa yang telah mengakar di masyarakat.

\section{SIMPULAN}

Berdasarkan hasil penelitian dapat disimpulkan bahwa drama Grafito cenderung absurd dan bertipe komedi satire. Konflik yang terjadi antartokoh disebabkan oleh perdebatan tentang perkawinan beda agama. Aspek religi dalam Grafito meliputi hubungan manusia dengan Allah/Tuhan, di antaranya meliputi akidah yang berujud cinta kepada Allah, percaya kepada Allah, dan berdoa. Terdapat juga hubungan manusia dengan manusia meliputi aspek religi, yaitu saling menolong antarsesama manusia; saling menghormati; dan toleransi antarumat beragama. Konsep religi budaya dalam Grafito adalah kepercayaan terhadap kekuatan gaib/kekuatan supranatural yang membuktikan bahwa budaya Jawa masih mengakar kuat dalam masyarakat.

\section{DAFTAR PUSTAKA}

Akhudiat. 2014. Antologi 5 Lakon Akhudiat. Lamongan: PAGAN PRESS.

Ahmadi, Abu. 2008. Dasar-dasar Pendidikan Agama Islam. Jakarta: Bumi Aksara.

Aminuddin. 2010. Pengantar Apresiasi Karya Sastra. Bandung: Sinar Baru Algensindo.

Azra, Azyumardi, dkk. 2002. Pendidikan Agama Islam pada Perguruan Tinggi Umum. Jakarta: Departemen Agama. 
Damono, Sapardi Djoko. 2009. Drama Indonesia: Beberapa Catatan. Jakarta; Editum.

Durkheim, Emile. 2011. The Elementary Forms of The Religious Life. Yogyakarta: IRCiSod.

Kaswadi. 2017. Ekologi Religi dalam Naskah-naskah Drama Karya Akhudiat. Dalam Inovasi. Volume XIX, 1 Januari.

Lathief, Supaat. 2008. Sastra: Eksistensialisme-Mistisisme Religius. Lamongan: Pustaka Ilalang.

Mangunwijaya. 1982. Sastra dan Religiusitas. Jakarta: Sinar Harapan.

Nata, Abudddin. 2010. Metodologi Studi Islam. Jakarta: PT Grafindo Persada.

Nurgiyantoro, Burhan. 2010. Teori Pengkajian Fiksi. Yogyakarta; UGM Gadjah Mada University Press.

Ratna, Nyoman Kutha. 2007. Teori, Metode, dan Teknik Penelitian Sastra. Yogyakarta: Pustaka Pelajar.

Rejono, Imam. 1996. Nilai-Nilai Religiusitas dalam Sastra Lampung. Jakarta: Pusat Pembinaan dan Pengembangan Bahasa.

Sari, Dian. 2011. Aspek Religiositas Novel Titian Nabi Karya Muhammad Masykur A.R Said Serta Hubungannya dengan Pembelajaran Apresiasi Sastra di SMA. Skripsi: FKIP Universitas Mataram.

Soemanto, Bakdi. 2007. "Absurditas dalam Lakon-lakon Indonesia”. Dalam Sapardi Djoko Damono, dkk. Absurditas dalam Sastra Indonesia. Jakarta: Pusat Bahasa depdiknas.

Stanton, Robert. 2007. Teori Fiksi. Yogyakarta: Pustaka Pelajar.

Sutopo. 2002. Penelitian Kualitatif. Surakarta: Sebelas Maret University Press. Zuhairini, Siti. 2007. Analisis Unsur Intrinsik dan Aspek Religiusitas Novel Selamah Karya Ali Ahmad Baktsir. Skripsi: FKIP Universitas mataram 